\title{
Sexuality of Women with Rheumatoid Arthritis in a West African Hospital
}

\author{
Aly Badra Kamissoko', Tayo Nadège Raissa Edikou', Abdoulaye Barry ${ }^{1}$, Marina Sanda ${ }^{1}$, \\ Kadé Fofana1, Lou Nahan Eunice Irie', Mamadou Lamine Diallo1,2, Owonayo Oniankitan² \\ ${ }^{1}$ Department of Rheumatology, Ignace Deen National Hospital, Conakry, Guinea \\ ${ }^{2}$ Department of Rheumatology, Sylvanus Olympio University Hospital, Lomé, Togo \\ Email: drkamissoko@ymail.com
}

How to cite this paper: Kamissoko, A.B. Edikou, T.N.R., Barry, A., Sanda, M., Fofana, K., Irie, L.N.E., Diallo, M.L. and Oniankitan, O. (2021) Sexuality of Women with Rheumatoid Arthritis in a West African Hospital. Open Journal of Rheumatology and Autoimmune Diseases, 11, 152-159. https://doi.org/10.4236/ojra.2021.114016

Received: August 13, 2021

Accepted: October 11, 2021

Published: October 14, 2021

Copyright $\odot 2021$ by author(s) and Scientific Research Publishing Inc. This work is licensed under the Creative Commons Attribution International License (CC BY 4.0).

http://creativecommons.org/licenses/by/4.0/

\begin{abstract}
Background: Rheumatoid arthritis is a chronic autoimmune disease that causes socio-economic, psychological and sexual problems. It imposes limitations on sexual relationships and these issues are still taboo in African society. Objective: The objective is to assess the impact of rheumatoid arthritis (RA) on women's sexuality at the Ignace Deen National Hospital. Patients and Methods: This was an analytic case-control study of 8 months (from April 6, 2020 to December 11, 2020). All patients followed for rheumatoid arthritis diagnosed according to 2010 ACR/EULAR criteria for RA had been included. Results: One hundred and five women (52 RA patients and 53 controls) were collected. The two groups were comparable in terms of demographic characteristics. Sexual dysfunction was found in $69.2 \%$ of cases versus $35.8 \%$ of controls. Women with RA had poorer sexual functioning in the categories of desire, arousal, lubrication, orgasm, satisfaction, and pain of the FSFI score compared to healthy women $(\mathrm{p}=0.01 ; \mathrm{p}=0.7 ; \mathrm{p}=0.3 ; \mathrm{p}=0.8 ; \mathrm{p}=0.1$; and $\mathrm{p}$ $=0.3$ respectively). Patients were 4 times more likely to have sexual dysfunction than healthy individuals and this result was statistically significant with a p-value less than 0.05. Conclusion: Sexual dysfunction was noted in a large number of RA patients surveyed at the rheumatology department of the Ignace Deen national hospital. A larger study is needed to better assess this issue and seek management solutions.
\end{abstract}

\section{Keywords}

Rheumatoid Arthritis, Sexuality, FSFI, Guinea

\section{Introduction}

Rheumatoid arthritis (RA) is a chronic and progressive autoimmune disease 
characterized by inflammation responsible for joint destruction, leading to functional disability and chronic pain [1]. RA causes socio-economic, psychological and sexual problems. Sexual problems are common, but also taboo, especially in African societies [2]. RA imposes limitations on sexual intercourse impacting sexual desire [3], and the main reasons cited are fatigue and pain [4]. This leads to a decrease in frequency of sexual intercourse [5]. In Sweden, decreased sexual desire was found in 62\% of women with rheumatoid arthritis [3]. In 2019 in Tunisia, Alia $\mathrm{F}$ et al. reported a decrease in sexual frequency in 59\% of women after diagnosis of RA [5]. In Senegal, 23.8\% of RA patients had a co-wife since the beginning of the disease course [6]. Several Guinean studies have dealt with RA without addressing the sexual dimension [7] [8] [9] [10]. The objective of this study was to assess the impact of RA on women's sexuality at the Ignace Deen national hospital in Conakry (Guinea).

\section{Patients and Methods}

This was an analytical case-control study lasting 8 months (from April 6, 2020 to December 11,2020) in the rheumatology department of the Ignace Deen national hospital in Conakry (Guinea). Patients followed for rheumatoid arthritis diagnosed according to the ACR/EULAR 2010 criteria [11] were included. We recruited all consenting patients, meeting the selection criteria. Controls were female volunteers in apparent good health, of the same age range as the cases. They were recruited among the patients' companions. One case (women with RA) was age-matched to a control (volunteer woman in apparent good health). Not included in the study were:

- Patients with gynecological disease.

- Patients whose partner has suffered from a urological disease.

- Patients with neurological or psychiatric illness.

- Patients on medication that may affect sexual function (antidepressants, neuroleptics).

- Patients diagnosed with secondary Sjögren's syndrome.

- For each patient, the following data were collected:

- Qualitative data: employment status, marital status, presence of a co-wife, education level.

- Quantitative data: age, RA duration, morning stiffness, number of swollen joints, number of tender joints, number of ankylosed joints, Disease Activity Score 28 (DAS28) which assesses the activity of rheumatoid arthritis in 28 joints. RA is considered in remission if DAS $28 \leq 2.6$, low active if $2.6<$ DAS $28 \leq 3.2$, moderately active if $3.2<$ DAS $28 \leq 5.1$ and highly active if DAS $28>5.1$. The Visual analogue scale (VAS) assesses the intensity of the patient's pain on a scale of 0 (no pain) to 10 (unbearable pain). The Health Assessment Questionnaire (HAQ) which assesses the functional impact of RA on the patients' quality of life. The score varies from 0 (patient maintains activities without difficulty) to 3 (patients unable to do activities). The Female Sexual Function Index (FSFI) score which assesses sexual function in women. 
FSFI consists of 19 questions divided into six subscales measuring different aspects of female sexual function. These aspects are desire (Q1 - Q2), arousal (Q3 - Q6), lubrication (Q7 - Q10), orgasm (Q11 - Q13), satisfaction (Q14 Q16) and pain (Q17 - Q19). When FSFI is less than or equal to 26.55, there is sexual dysfunction [12] [13]. The short form of the FSFI was used. This version was based on existing FSFI items (desire, arousal, lubrication, orgasm, satisfaction and pain). A total score of 19 is diagnostic of sexual dysfunction, with a maximum score of 30 [14].

\subsection{Data Analysis}

The results were analysed using Microsoft Excel 2019 and Epi Info 7.2.3.1. Qualitative variables were summarised by frequency and percentage, and quantitative variables by mean and standard deviation (SD). Comparisons were made by using the Pearson correlation test. All tests were two-tailed; the significance level was set at $5 \%$.

\subsection{Ethical Considerations}

Informed consent was obtained from the patients and the research protocol was accepted by the ethics committee of the Ignace Deen national hospital in Conakry.

\section{Results}

One hundred and five women were registered (53 cases and 53 controls). The mean age of the patients was $43.3 \pm 13.4$ (Range: 18 years and 73 years). There was a predominance of married patients (71.2\%) with an average duration of marriage of $18.6 \pm 11.3$ years. They had a co-wife in $54.1 \%$ of cases. RA patients were employed in $57.7 \%$ of cases (Table 1 ).

The RA average duration was $6.7 \pm 6.2$ years. The mean DAS 28 at the time of evaluation was $4 \pm 1.6$ (Table 2).

Cases had significant sexual dysfunction $(\mathrm{p}=0.00006)$. The scores used found that 36 patients (69.2\%) and 19 controls (35.8\%) had a sexual dysfunction. All dimensions of sexuality were affected. The lower the mean scores, the more the domain were impacted. Desire, arousal, lubrication, orgasm, satisfaction and pain were all lowered in RA patients than in controls. The most affected part was desire, which was correlated with RA with a p-value of 0.01 (Table 3).

Thirty-seven patients under 50 years had a sexual dysfunction $(45.7 \%)$ compared to 19 over 50 years. Sexual dysfunction was correlated with patient age with a p-value $<0.05(\mathrm{p}=0.0039)$. The limitation of patients' quality life, calculated by the HAQ score was not significantly associated with the occurrence of sexual dysfunction $(\mathrm{p}=0.376)$ (Table 4).

\section{Discussion}

This was a case-control study to investigate the sexuality of women with rheumatoid arthritis in the rheumatology department of the Ignace Deen national 
Table 1. Socio-demographic characteristics of rheumatoid arthritis patients and controls.

\begin{tabular}{ccc}
\hline & Cases n (\%) & Controls n (\%) \\
\hline Age (mean \pm standard deviation) & $43.3 \pm 13.4$ & $36 \pm 13$ \\
Marital status & & \\
Single & $7(13.5)$ & $21(39.6)$ \\
Divorced & $2(3.8)$ & $2(3.8)$ \\
Married & $37(71.2)$ & $27(50.9)$ \\
Widowed & $6(11.5)$ & $3(5.7)$ \\
Duration of marriage & $18.6 \pm 11.3$ & $17.5 \pm 12.7$ \\
Co-wife & & $17(63)$ \\
Yes & $20(54.1)$ & \\
No & $17(45.9)$ & $8(15.1)$ \\
Educational stage & & $45(84.9)$ \\
Illiterate-Primary & $16(30.8)$ & $26(49.1)$ \\
Secondary-Higher & $36(69.2)$ & $27(50.9)$ \\
Professional status & & \\
Employee & $30(57.7)$ & \\
Unemployed & $22(42.3)$ & \\
\hline
\end{tabular}

Table 2. Clinical characteristics of the 52 patients with RA.

\begin{tabular}{ccc}
\hline & $\mathrm{n}(\%)$ & Mean $\pm \mathrm{SD}$ \\
\hline RA duration (years) & & $6.7 \pm 6.2$ \\
Age of onset (years) & & $35.9 \pm 13.9$ \\
Morning stiffness & $26(55.3)$ & \\
$<30$ min & $21(44.7)$ & \\
$\geq 30$ min & & $1 \pm 21.7$ \\
Ankylosed joints & & $7 \pm 9$ \\
Tender joints & & $2 \pm 3$ \\
Swollen joints & $4.0 \pm 1.6$ \\
DAS28 & $4.0 \pm 2.9$ \\
VAS & & $0.7 \pm 0.8$ \\
HAQ & &
\end{tabular}

DAS28: Disease activity score 28; VAS: Visual analogue scale; HAQ: Health assessment questionnaire.

Table 3. Comparison of the overall score and mean scores of the different FSFI domains between cases and controls.

\begin{tabular}{cccc}
\hline & Cases $(\mathrm{n}=52)$ & Controls $(\mathrm{n}=53)$ & p-value \\
\hline RA duration (years) & $2.5 \pm 1.1$ & $3.0 \pm 1.2$ & 0.01 \\
\hline
\end{tabular}




\section{Continued}

\begin{tabular}{cccc}
\hline Age of onset (years) & $1.5 \pm 1.7$ & $2.8 \pm 1.9$ & 0.7 \\
Morning stiffness & $1.7 \pm 2.0$ & $3.2 \pm 2.0$ & 0.3 \\
$<30 \mathrm{~min}$ & $1.3 \pm 1.8$ & $2.8 \pm 1.9$ & 0.8 \\
$\geq 30 \mathrm{~min}$ & $2.5 \pm 1.7$ & $3.7 \pm 1.7$ & 0.1 \\
Ankylosed joints & $1.7 \pm 2.1$ & $3.0 \pm 1.9$ & 0.3 \\
Tender joints & $11.3 \pm 9.4$ & $18.5 \pm 9.7$ & 0.0006 \\
Swollen joints & & & \\
\hline
\end{tabular}

Table 4. Sexual dysfunction by age and HAQ in women with rheumatoid arthritis and in healthy women.

\begin{tabular}{cccc}
\hline & $\begin{array}{c}\text { Age 18 - 50 years } \\
\mathrm{n}(\%)\end{array}$ & $\begin{array}{c}\text { Age 51 - 73 years } \\
\mathrm{n}(\%)\end{array}$ & p-value \\
\hline Presence of sexual dysfunction & $37(45.7 \%)$ & $19(79.2 \%)$ & 0.0039 \\
No sexual dysfunction & $44(54.3 \%)$ & $5(20.8 \%)$ & \\
\hline Presence of sexual dysfunction & $25(65.8 \%)$ & $11(78.6 \%)$ & 0.376 \\
No sexual dysfunction & $13(34.2 \%)$ & $3(21.4 \%)$ & \\
\hline
\end{tabular}

hospital in Conakry, Guinea. This study collected hospital data that cannot be extrapolated to the general population. Our department is the unique rheumatology department in Guinea but the patients do not consult systematically. In their journey to treatment, they still require a lot to traditional medicine before coming to medical structures. The consideration by the subject of sexuality as a taboo in our society was another limitation in collecting data such as talking about sexuality to a third person especially in Guinea. Interview by a woman helped to remove this barrier. The frequency of sexual dysfunction in patients was similar to Moroccan data [15] (71.9\% for cases vs. 54\% for controls). Similarly, in Turkey, a high frequency of sexual dysfunction was reported [16]. This high frequency could be explained by the fact that pain, fatigue and stiffness are the main signs of RA, thus putting sexuality at the bottom of the priority list. The mean age of the patients was comparable to that of Kars Fertelli T [16] (49.5 \pm 8.14 years) and Frikha $\mathrm{F}$ et al. [17] (42.5 \pm 5.8 years). This result could be explained by the fact that, according to literature, RA most often affects women in the age group between 40 and 60 years [18]. The high frequency of married women was similar to the data reported by Lin M-C et al. [19] (92.9\%). This could be explained by the fact that the religious context of the population for who marriage is a very important value in the custom. The marriage average duration was similar to the Egyptian report [20] (18.5 \pm 3.5 years; range: 3 and 37 years) and the Tunisian data [17] (17.7 years; range: 2 and 28 years). In our context, women marry ant a young age. The high co-wife rate has been reported 
in Senegal (23.8\%) [6]. The symptoms of the disease influence the relationship between the spouses. This would lead the husband, not satisfied with his sex life in general to take another wife. The impact of RA on patients' life quality was lower than that reported in Turkey $[21](\mathrm{HAQ}=1.3 \pm 0.7)$. This low frequency could be explained by the fact that most patients are quickly diagnosed and immediately started on treatment. This would significantly reduce the impact of RA on their quality of life. The moderate disease activity was thought to be related to the fact that patients most often return to their doctor when they experience symptoms of the disease. The low sexual desire of RA patients compared to controls was similar to the data of Aras $\mathrm{H}$ et al. [22] (cases $2.1 \pm 0.9$ vs. controls $3.02 \pm 0.8$ ). This low sexual desire in female RA patients could be explained by the cognitive and emotional aspects of sexual desire, which are often altered during chronic diseases [5]. Sexual arousal in patients was lower than in Tunisian patients [5] (3.27 \pm 1.5$)$. This could be due to the decreased libido caused by RA, always associated with the importance of joint pain, hence a decrease in arousal [23]. Low sexual lubrication in patients was lower than in Turkey [16] (cases $3.52 \pm 0.99$ vs. controls $3.54 \pm 1.08$ ). This may be related to the fact that RA may be accompanied by mucocutaneous dryness. The patients and controls had a lower orgasm than the Moroccan patients [24] (cases $3.86 \pm 1.47$ vs. controls $2.70 \pm 1.80$ ). This low score comes from fatigue and joint pain that would prevent patients from experiencing sufficient pleasure during sexual activity. This concept of orgasm, which can sometimes be difficult to define, was however well understood by our respondents. Contrary to the parameters described above, the patients' sexual satisfaction was comparable to the data of Aras $\mathrm{H}$ et al. [22] (cases $2.05 \pm 0.9$ vs. controls $3.9 \pm 1.3$ ). This low sexual satisfaction could be explained by the patients' fear of pain related to movements. They would prefer to shorten the duration of sexual intercourse, which would lead to dissatisfaction [25]. Our patients had more pain during vaginal penetration than those of Coskun B et al. [26] (cases $4.26 \pm 1.77$ vs. controls $5.50 \pm 0.56$ ). The fact that the patients were not sufficiently lubricated they could experience pain during vaginal penetration. The high risk of sexual dysfunction in patients with RA would be related to the main symptom of RA: pain; but also to the psychological state of patients. There was a correlation between age and sexual dysfunction which is much more prevalent in young people. This is because in general, older women are less sexually active than younger ones.

\section{Conclusion}

Rheumatoid arthritis is chronic inflammatory rheumatism and its symptoms have a significant impact on the sexuality of women who suffer from that condition, because of the functional handicap it causes. The absence of studies on this aspect in Guinea led us to highlight the negative impact of this disease on sexuality. A larger study is needed to better assess this issue and seek management solutions. 


\section{Conflicts of Interest}

The authors declare that they have no conflicts of interest.

\section{References}

[1] Weber, A. and De Bandt, M. (2000) Angiogenèse: Mécanismes Généraux Et Implications Au Cours De La Polyarthrite Rhumatoïde. Revue du Rhumatisme, 67, 573-592. https://doi.org/10.1016/S1169-8330(00)00015-6

[2] Tristano, A.G. (2009) The Impact of Rheumatic Diseases on Sexual Function. Rheumatology International, 29, 853-860. https://doi.org/10.1007/s00296-009-0850-6

[3] Josefsson, K.A. and Gard, G. (2012) Sexual Health in Patients with Rheumatoid Arthritis: Experiences, Needs and Communication with Health Care Professionals. Musculoskeletal Care, 10, 76-89. https://doi.org/10.1002/msc.1002

[4] Hill, J., Bird, H. and Thorpe, R. (2003) Effects of Rheumatoid Arthritis on Sexual Activity and Relationships. Rheumatology, 42, 280-286. https://doi.org/10.1093/rheumatology/keg079

[5] Alia, F., Rim, B.S., Miladi, S., Ouenniche, K., Kassab, S., Chekili, S., et al. (2019) Comparison of Sexual Function in Tunisian Women with Rheumatoid Arthritis and Healthy Controls. Clinical Rheumatology, 38, 3361-3365. https://doi.org/10.1007/s10067-019-04726-8

[6] Ndao, A.C., Ndongo, S., Lekpa, F.K., Ndiaye, N.D. and Tiendrebeogo, J. (2012) Retentissement Socio-Économique Et Qualité De Vie Au Cours De La Polyarthrite Rhumatoïde Au Sénégal. Médecine d Afrique Noire, 59, 415-420.

[7] Kamissoko, A.B., Diallo, M.L., Traoré, M., Diallo, A., Yombouno, E., Barry, A., et al. (2018) Panorama Des Maladies Rhumatismales A Conakry. European Scientific Journal, 14, 422-431. https://doi.org/10.19044/esj.2018.v14n24p422

[8] Traoré, M., Diallo, A., Kamissoko, A.B., Eloundou, P. and Diallo, M.L. (2020) Comparison between Different Disease Activity Scores in Black African Patients with Rheumatoid Arthritis: A Cross-Sectional Multicenter Study. Journal of Rheumatic Diseases and Treatment, 6, Article No. 084. https://doi.org/10.23937/2469-5726/1510084

[9] Kamissoko, A.B., Diallo, M.L., Oniankitan, S., Baldé, N., Traoré, M., Yombouno, E., et al. (2019) Prise En Charge Des Rhumatismes Inflammatoires Chroniques En Guinée. Journal de la Recherche Scientifique de I Université de Lomé, 21, 385-392.

[10] Kamissoko, A.B., Eloundou, P., Traoré, M., Diallo, M.L., Mendo, G., Diallo, M.F., et al. (2021) Profil Et Qualité De Vie De Patients Atteints De Polyarthrite Rhumatoïde En Guinée Conakry Et Au Cameroun. The Pan African Medical Journal, 38, Article No. 379. https://doi.org/10.11604/pamj.2021.38.379.20098

[11] Hua, C. and Combe, B. (2017) Les Nouveaux Critères De Classification ACR/EULAR 2010 Pour Un Diagnostic Plus Précoce De La Polyarthrite Rhumatoïde. Revue du Rhumatisme Monographies, 84, 337-342. https://doi.org/10.1016/j.monrhu.2017.07.001

[12] Rosen, R. (2000) The Female Sexual Function Index (FSFI): A Multidimensional Self-Report Instrument for the Assessment of Female Sexual Function. Journal of Sex \& Marital Therapy, 26, 191-208. https://doi.org/10.1080/009262300278597

[13] Trudel, G., Dargis, L., Cadieux, J., Villeneuve, L., Préville, M. and Boyer, R. (2012) Validation De l'Index De La Fonction Sexuelle Féminine (IFSF) Et Présentation De Normes Chez Les Femmes Aînées. Sexologies, 21, 161-167. https://doi.org/10.1016/j.sexol.2012.01.003 
[14] Isidori, A.M., Pozza, C., Esposito, K., Giugliano, D., Morano, S. and Vignozzi, L. (2010) Development and Validation of a 6-Item Version of the Female Sexual Function Index (FSFI) as a Diagnostic Tool for Female Sexual Dysfunction. The Journal of Sexual Medicine, 7, 1139-1146. https://doi.org/10.1111/j.1743-6109.2009.01635.x

[15] Khnaba, D., Rostom, S., Lahlou, R., Bahiri, R., Abouqal, R. and Hajjaj-Hassouni, N. (2016) Sexual Dysfunction and Its Determinants in Moroccan Women with Rheumatoid Arthritis. The Pan African Medical Journal, 24, Article No. 16. https://doi.org/10.11604/pamj.2016.24.16.9081

[16] Fertelli, T.K. (2020) Effects of Education about Rheumatoid Arthritis and Sexuality on the Sexual Problems of Women with Rheumatoid Arthritis. Clinical Nursing Research, 29, 189-199. https://doi.org/10.1177/1054773819858493

[17] Frikha, F., Maazoun, F., Salah, R.B., Snoussi, M., Masmoudi, J., Mhiri, M.N., et al. (2011) Dysfonction Sexuelle Chez Dix Femmes Mariées Atteintes De Polyarthrite Rhumatoïde. La Presse Médicale, 40, e521-e527. https://doi.org/10.1016/j.lpm.2011.04.015

[18] Sany, J. (2003) La Polyarthrite Rhumatoïde De L'adulte-Conception Actuelle. 2ème Edition, John Libbey Eurotext (Paris), Montrouge.

[19] Lin, M.-C., Lu, M.-C., Livneh, H., Lai, N.-S., Guo, H.-R. and Tsai, T.-Y. (2017) Factors Associated with Sexual Dysfunction in Taiwanese Females with Rheumatoid Arthritis. BMC Women's Health, 17, Article No. 12. https://doi.org/10.1186/s12905-017-0363-5

[20] Essam, A., Selim, Z., Teleb, S., Zaghira, M., Fawzy, M. and Hamed, S. (2016) Sexual Function in Females with Rheumatoid Arthritis: Relationship with Physical and Psychosocial States. Archives of Rheumatology, 31, Article No. 239. https://doi.org/10.5606/ArchRheumatol.2016.5838

[21] Yilmaz, H., Polat, H.A.D., Yilmaz, S.D., Erkin, G., Kucuksen, S., Salli, A., et al. (2012) Evaluation of Sexual Dysfunction in Women with Rheumatoid Arthritis: A Controlled Study. The Journal of Sexual Medicine, 9, 2664-2670. https://doi.org/10.1111/j.1743-6109.2012.02882.x

[22] Aras, H., Aras, B., Icagasioglu, A., Yumusakhuylu, Y., Kemahli, E., Haliloglu, S., et al. (2013) Sexual Dysfunction in Women with Rheumatoid Arthritis. Medicinski Glasnik, 10, 327-331.

[23] van Berlo, W.T., van de Wiel, H.B., Taal, E., Rasker, J.J., Schultz, W.C.W. and van Rijswijk, M.H. (2007) Sexual Functioning of People with Rheumatoid Arthritis: A Multicenter Study. Clinical Rheumatology, 26, 30-38. https://doi.org/10.1007/s10067-006-0216-3

[24] Hari, A., Rostom, S., Lahlou, R., Bahiri, R. and Hajjaj-Hassouni, N. (2015) Sexual Function in Moroccan Women with Rheumatoid Arthritis and Its Relationship with Disease Activity. Clinical Rheumatology, 34, 1047-1051. https://doi.org/10.1007/s10067-015-2888-z

[25] Helland, Y., Dagfinrud, H. and Kvien, T.K. (2008) Perceived Influence of Health Status on Sexual Activity in RA Patients: Associations with Demographic and Disease-Related Variables. Scandinavian Journal of Rheumatology, 37, 194-199. https://doi.org/10.1080/03009740701867349

[26] Coskun, B., Coskun, B.N., Atis, G., Ergenekon, E. and Dilek, K. (2014) Evaluation of Sexual Function in Women with Rheumatoid Arthritis. Urology Journal, 10, 1081-1087. 